\title{
A Platform for Partnership: Preparing Student Teachers for Parent-Teacher Participation
}

\author{
Marais Petro \\ Department of Early Childhood Education and Development \\ University of South Africa
}

\section{Doi:10.5901/jesr.2013.v3n7p419}

\begin{abstract}
If student teachers are not made aware of and are not given an opportunity to experience the fundamental connection between teachers and parents, their professional development during the training years is actually incomplete. Preparing student teachers for parent-teacher participation is, however, not a straightforward process. Getting student teachers involved in this unique relationship is challenging and can even be stressful for them. Student teachers should be equipped with the necessary skills, knowledge and strategies during their training years to be able to recognise and encourage the benefits of home-school participation (Van Wyk \&Lemmer, 2009:14). Student teachers do not only need opportunities to prepare and present lessons during their teaching practice periods at schools. They also need learning experiences that would help them to encourage, promote and show consideration for parent involvement. Therefore, the specific aim of the research under review focuses on identifying possible learning opportunities for student teachers during their teaching practice at schools that will enable them to acquire the ability to respect, value and admire parent participation. This paper addresses the following research question: What challenges with regard to engaging student teachers in parent involvement do mentor teachers experience and what learning opportunities can be provided to student teachers to enable them to manage parent-teacher partnerships? In order to answer this question a qualitative research approach was used. Both the socio-constructivist learning and Lave and Wenger's situated learning theory were used as theoretical frameworks. A maximum variation sampling technique was used to purposefully select 10 mentor teachers from functional urban schools as participants who viewed themselves as role models for student teachers. The findings suggest that practice should be viewed as activity embedded in theory. Findings also indicate that the preparation of student teachers for parent-teacher partnership demands systematic action and thoughtful, coordinated planning. The research concludes with suggestions for ways to provide learning opportunities for student teachers that could play a significant role in guiding and preparing them to respect and promote home-school partnership.
\end{abstract}

Keywords: Home-school relationship, parent involvement, student teachers, teacher-parent relationship, teaching practice

\section{Introduction}

Teacher training institutions should determine whether they are producing appropriate made-to-measure skills that will enable student teachers to educate learners to internationally competitive levels when entering the teaching profession. Teaching practice (also called cooperative education, extension service placements, field education, internships, and practicum), is an essential component of teacher training programmes. Research done by Du Plessis, Marais, Van Schalkwyk and Weeks (2010:336-338) determined that teaching practice activities need to address all aspects of teaching in order to train competent teachers for the teaching profession. During teaching practice periods student teachers must experience numerous situations in which they engage with teaching activities in order to understand the real exercise of reflecting rationally and displaying the skills, knowledge and attitudes required for the teaching profession. Therefore they need to also deal with the challenges of parent involvement. Being engaged in parent involvement during teaching practice periods at schools will help them to acquire the necessary experiences, knowledge and attitudes to appreciate and respect as well as manage parent involvement for the benefit of the learner, the parents and the teacher.

For the purpose of this research project the teaching practice component of the BEd (Intermediate Phase) at an open distance learning institution in South Africa was used to gain information from mentor teachers regarding parent involvement of student teachers. Teaching practice in this BEd qualification consists of four year-modules which each require five weeks of teaching practice. This means that a student has completed 20 weeks of teaching practice in schools by the end of the BEd programme and thus on his/her entry into the teaching profession. 
This research was driven by the following research question: What learning opportunities can be provided to student teachers to enable them to effectively manage parent-teacher partnerships?

As far as could be determined, research which addressed this issue has to date not focused on ODL students. This study hopes to fill this gap in research by identifying activities to promote student teachers' ability to engage in parent involvement during teaching practice periods at schools. If this gap is not addressed, ODL student teachers may remain unaware of their responsibility to engage in and reflect on parent involvement. On the other hand, appropriate learning experiences during teaching practice periods will enable student teachers to acquire the necessary knowledge and skills as well as a positive attitude towards parent involvement. Thus, the aim of this research was to identify learning opportunities that can enable student teachers to engage and manage parent-teacher partnerships during their teaching practice periods at schools. This research addresses the following: the conceptual framework of the study; a literature review of parent involvement; the research design of the investigation, the findings and lastly the conclusions.

\section{Theoretical Framework and Literature Review}

Two learning theories supported this study namely, the socio-constructivist learning theory and Lave and Wenger's situated learning theory and its value is being explained according to the theme of this research. The socio-constructivist viewpoint on learning refers to learning as an on-going, energetic process of learners (student teachers) in constructing meaning and transforming understandings (about parent involvement and parent partnerships) while interacting with the environment (the school as a teaching and learning environment and reality). This is an active responsibility in constructing knowledge (about dealing with parent involvement). Moreover learning is collaborative and learners (student teachers) learn from their mentors (mentor teachers) and one another (other student teachers). Socio-constructivists also argue that the individual (student teachers' own) construction of knowledge (in this case, about parent involvement) always occurs in social contexts (in the school or community), because learning activities are socially and contextually bound. There should be a continuous reciprocal interaction to ensure that the learning process is productive and successful. Clearly, this theory is in favour of student-centred teaching and learning and places the learners' (student teachers') own efforts to understand (the phenomenon of parent partnership) at the centre of educational events (Woolfolk, 2007: 481).

Furthermore, socio-constructivists believe that learners (student teachers) should deal with complex real-life situations (problems, concerns and needs of the learners and their parents/caregivers). They need ample opportunities to engage in meaningful, problem-based activities. Student teachers therefore need sufficient time and mentoring during teaching practice periods to address the reality of parent involvement in a significant way during teaching practice periods. Their ideas should also be elicited in respect of the above (Collins, Brown \& Holum, 1991:38-39). When engaging with parents, student teachers are asked to apply knowledge in diverse and authentic contexts, to interpret attitudes and problems and to construct arguments based on evidence. They continually need to articulate their knowledge and understanding and consult various resources. Student teachers should also work collaboratively and support one another when dealing with parents' concerns, problems and needs. Supporters of the socio-constructivist approach emphasise that mentors (mentor teachers) make their own thinking processes explicit to learners (student teachers) and encourage them to do the same.

The second theory that supported this study was the situated learning theory of Lave and Wenger (1991). Lave and Wenger $(1991: 32,59,70)$ view learning as a social process where uniqueness, membership (a need to belong in order to learn) and inter-personal relationships are significant. This theory is based on two inter-related beliefs. The first is that learning takes place in accordance to context, culture and the activity in which it occurs, and the second is that learning is a process that occurs in a participatory social context. The two parties involved in situated learning are the "master teachers" (mentor teachers) and the "apprentices" (student teachers). Learners (student teachers) acquire the knowledge and skills (about parent partnerships) that is required from them to perform in the classroom by engaging in the school situation (which includes participation in parent involvement). They have to apply the knowledge, skills and attitudes by engaging in real-life situations (the reality of parent partnerships).

Two concepts are relevant for situated learning theory, namely, "community of practice" and "legitimate peripheral participation". Learners (student teachers) develop and identify with the practices appropriate for a specific community (parents). Wenger identifies three elements that define a community of practice, namely, mutual engagement of participants in action, negotiation of a joint enterprise and development of a shared repertoire. Student teachers are legitimate peripheral participants in the practices of the teaching community during their teaching practice periods under the supervision of experienced mentor teachers. The two theories, discussed above together with the literature study will 
be used to interpret the findings.

The following section contains a brief review of relevant literature. The focus is on the benefits and challenges of parent involvement for the learner, parent, and student teacher.

\subsection{The importance of parent involvement}

The most effective teaching and learning take place when parents and teachers, thus families and schools work together. The learner always was and is still the most important person in education and every teaching and learning activity circles around the learner.

Parent involvement in early childhood education not only influences positive cognitive and social development but also helps young children to achieve their full potential (Driessen, Smit \& Sleegers, 2005). Learners who receive parental attention and support in the early years of learning are more able to deal with school work independently later. Parent involvement leads to greater academic success. Children are usually keen to participate in activities when their parents are involved (Singh, Mbokodi \& Msila, 2004:305).

Lemmer (2009:12) indicates that children benefit significantly in all aspects of school life when their parents are involved in their education. Gordon and Brown (2011:263) agree. Young children whose parents choose to become actively involved in school activities, reap the rewards and share in the success of their children (bonding experience). Clearly therefore, educational goals for young learners can be best achieved if parents are involved in their child's preschool years (Gordon and Brown (2011:263).

\subsection{The need for student teachers to participate in parent involvement}

Many teacher training programmes at universities include either a separate module on parent involvement or as a part of another module. Unfortunately these modules are not always incorporated into the teaching practice component of the training programmes, and student teachers do not learn to communicate and engage with parents. To teach student teachers to address the needs of school learners from diverse cultural backgrounds is a challenge that cannot be underestimated. Not only are some school learners the children of immigrants, but in many cases English is not their mother tongue and, moreover, the learners also come from various religious backgrounds. Therefore training institutions should invest in the strengths and motivations of student teachers during their teaching practice periods at schools in order to best prepare them to participate in parent involvement (Caspe, Lopez, Chu \& Weiss, 2011:1).

Parent involvement can be seen as a partnership between school and home and must be embedded in as system of training for professional development. According to (Caspe et al., 2011:2) five fundamental elements in the system are the following:

- Standards for family engagement: National professional standards that define what educators should know and be able to do when involved with parents must be in place. Currently the knowledge, skills and attitudes taught in teacher training programmes are left up to the discretion of each teacher training institution.

- A curriculum that teaches the skills, knowledge and attitudes that teachers need to engage with families: According to Caspe et al. (2011:3), numerous ways to prepare student teachers for engagement with families have already been identified. Most universities give lessons in parent involvement through coursework, or via field experiences with families. Thus the message is clear: a curriculum that advances teaching skills regarding practical family involvement during the training years is critical.

- Collaborations among the various stakeholders: Training of student teachers with regard to the engagement between school and home requires involvement among various stakeholders, namely, the service providers for teacher training in higher education, school districts and schools, community-based organisations and parents. Colloboration between the training institution and schools is needed so that student teachers are placed with schools that will allow them to engage with the parents of learners in their classes. Furthermore, support systems must be offered at universities to conduct research in order to suggest best practices and strategies for family engagement with curriculum committees.

- Continuing professional development around parent engagement: Student teachers' experiences during teaching practice periods are not enough. Educators, such as practising teachers and faculty members at post-secondary institutions, must continue researching and thus expanding their knowledge and skills about the effect that parent engagement has on student success. To strengthen the parent engagement skills of both student teachers and teachers, they can be encouraged to become partners in community outreach 
projects.

- Evaluation for learning and continuous improvement: Evaluation of parent involvement is important because it provides knowledge of how prepared student teachers and other educators are to partner with families. It informs higher education institutions about the areas of parent engagement where student teachers and teachers are doing well and also about where they require support. Such information is useful in order to adapt and improve the relevant curriculum that deals with teacher-parent partnerships. According to Caspe et al. (2011:3) some teachers are not trained in dealing with the problems, needs and challenges of families of learners in their classes. To assign tasks during teaching practice, student teachers can be trained to do this.

According to Caspe et al. (2011:1), student teachers are concerned that they start their teaching career without the necessary skills and knowledge regarding parent involvement and these students identified practical experiences of parent involvement during teaching practice periods as one of the top strategies to improve teacher training programmes. Against the background of the theoretical framework and the literature review, the following methodology was deemed suitable for investigating the views of mentor teachers regarding the matter of preparing student teachers for parentteacher participation.

\subsection{Research design}

The research employed a qualitative research approach using a phenomenological research design to obtain an understanding of the views of mentor teachers in the matter of preparing student teachers for parent-teacher participation. Purposeful sampling was used to select 10 information-rich mentor teachers as participants. These participants were selected because they identified themselves as role models for student teachers in a questionnaire which was inserted in one of the teaching practice workbooks and also because they teach in four functional urban schools which are usually selected by quite a number of student teachers for their teaching practice. One focus group interview was conducted at one of the schools. Written consent was obtained from the Department of Education and also from the school principals of the 4 schools where the teachers teach. Individual oral permission to audiotape the interview was obtained from all the participants. The interview was conducted in a conversational manner and began with an explanation of the purpose of the interview, a promise of confidentiality and a reassurance that there were no right or wrong answers. Only two questions were asked, namely: (1) What are the challenges you are currently experiencing when students participate in parent involvement? and (2) What learning opportunities do you provide to help student teachers acquire the ability to respect, value and manage parent involvement? Different tactics were used to eliminate bias. These included a mechanically recording interview and transcribing it verbatim. Member checking was also done after the study by sending the results to the participants so that they could determine whether their contributions had been interpreted correctly.

\section{Findings and Discussion}

The findings fell into two main themes according to the two questions asked in the focus group interview, namely, current challenges experienced by mentor teachers regarding student teachers' participation in parent involvement and learning opportunities for student teachers suggested by the mentor teachers

\subsection{Current challenges experienced by mentor teachers regarding student teachers' participation in parent involvement}

The first question was intended to determine the current challenges experienced by mentor teachers regarding the participation of student teachers in parent involvement. The participants were in agreement that the parents had doubts about student teachers' ability and knowledge to engage with them, the parents. Two of the participants also pointed out that they, as teachers, actually do not have enough time to promote and support student teachers' involvement with parents. One 40-year-old participant also pointed out that the student teachers are not always interested in participating in parent involvement. She maintained that the student teachers only wanted to present lessons in order to complete their teaching practice workbooks. Another participant, a 35-year old female, confessed that she feels uncertain of how to mentor student teachers in the matter of parent involvement. The following are the actual statements made by the participating mentor teachers in this regard:

- One student teacher had to deal with a parent who had doubts about her abilities. This problem was not one I had anticipated and felt unprepared to reassure this mother. 
- I did not know that student teachers are allowed to talk to parents

- I do not have time to involve student teachers when I work with parents.

- I think that parents might be doubtful of a student teacher's experience. Parents prefer to talk to me.

- Student teachers only want to present the required lessons and are not interested in dealing with the parents

- I think parents might be doubtful of a student teacher's experience

From the findings above it is clear that the current challenges regarding student teachers' participation in parent involvement during teaching practice periods at schools involve all three parties: the mentor teachers, the student teachers and the parents. Two participants thought that the parents were hindering and obstructing the involvement of student teachers because they did not trust the student teachers and they accused the student teachers of incompetency. Ignorance and unawareness of the responsibilities of a mentor teacher were also problems that emerged from the answers.

A serious problem that the mentor teachers pointed out was the fact that some student teachers do not want to get involved in anything other than completing their assignments as set out in the workbooks and are not interested in activities that are not required by the training institution. From the answers of the participating mentor teachers, it seems as if some students want to avoid activities that are not set out in their teaching practice workbooks. This is most unfortunate because student teachers who do not want to be involved in experiences with parent partnerships deprive themselves of valuable learning opportunities that will ultimately improve their ability to support the learners in their care. It is a teacher's duty and calling to put the learners in the centre of all activities and it is for the learners' benefit to strengthen home-school relationships.

In terms of the socio-constructivist theory on learning, interacting with the social environment is an important part of knowledge construction. The school as a teaching and learning environment is the heart of a community and student teachers need to take responsibility for constructing their own knowledge during teaching practice periods. Furthermore, socio-constructivists believe that student teachers should deal with complex, real-life situations, thus with the problems, concerns and needs of the learners and their families. These aspects should be part of student teachers' experiences during their training years.

The reports from the participants regarding the student teachers' reluctance to be involved in parent partnerships also runs counter to one of the previously mentioned guidelines of Caspe et al (2011:3), namely, that the teacher training curriculum should include activities that teach students the skills needed to engage with parents during the teaching practice periods. A curriculum that advances the skills, knowledge and attitudes of student teachers by including compulsory assignments during teaching practice periods will contribute towards and advance the professional development of student teachers.

As the mentor teachers pointed out, parents are actually also to blame for the fact that students are not involved in engaging with parents because they, the parents, prefer to engage with the teachers. It could be that parents underestimate student teachers' insight and their ability to show understanding. The fact, however, is that student teachers have chosen to become educators and it is part of their training to become problem solvers in the life of every learner. Under the careful guidance of mentor teachers it is possible that student teachers can provide valuable support to parents.

\subsection{Learning opportunities for student teachers provided by mentor teachers}

The object of the second question posed to the participants was to determine the learning opportunities provided by the mentor teachers. Although all participants acknowledged that they do not go to a great deal of trouble to promote parent involvement with student teachers, they nevertheless recommended the following:

- I will provide clear guidelines for communication with parents.

- I will motivate student teachers to attend parent/teacher meeting.

- Teachers need to inform parents about the student teachers who will be doing their teaching practice in the class.

- I will help parents to understand the responsibilities of student teachers.

- I will focus on the importance of communication with parents, such as weekly class newsletters, e-mails, and sms messages.

- I will observe student teachers cooperating with parents and discuss their input afterwards.

- I will guide the student teachers to write a letter to introduce herself to the parents

- Mentor teachers need to be concerned with student teachers' ability to work with parents from different cultural 


\section{backgrounds}

The suggested learning opportunities identified by the participants can be categorised into 4 aspects, namely, giving information about the student teachers to the parents; providing clear guidelines to student teachers about activities that promote parent involvement; explaining ways of communication with parents; and motivating student teachers to get involved with parents and to acknowledge the needs of parents from different cultural backgrounds.

Only one participant identified the need for mentoring student teachers in the skills of working with parents from different cultural backgrounds. In South Africa it is imperative for teachers to be able to be unbiased and to have respect for diversity. The situated learning theory lends itself well to teaching practice because it recognises that learning can be a social process where uniqueness, membership and inter-personal relationships are significant and where learning can take place in accordance to context, culture and the activity in which it occurs.. The two parties in the process associated with teaching practice are the mentor teachers (the "masters") and the student teachers (the "apprentices"). In teaching practice, the students acquire knowledge, skills and attitudes by engaging in real-life social situations of which parent involvement is an essential part.

The answers of the participants also pointed to the call mentioned above that Caspe et al (2011:3) made, namely, that field experiences with families need to be part of the training for professional development of student teachers. Caspe et al (2011:3) maintained that there are numerous ways to prepare student teachers for parent engagement. Such ways must be taught to students and included as practical activities to be carried out during their teaching practice period

\section{Conclusions and Recommendations}

From the findings of my research as reflected in the answers of the participating mentor teachers, it is clear that the practical training of student teachers needs to be revised so that student teachers are provided with learning opportunities which will enable them to manage parent-teacher partnerships. Student teachers must be made aware of the nature of parent involvement, how to engage with parents and the benefits, the barriers and the challenges that are involved. Real-life sensitive personal information should, however, not be given to students. Instead they can be replaced with make-believe scenarios. Mentor teachers need in-service training in this regard.

Another issue that needs to be addressed is incorporating activities for parent engagement in the teaching practice workbooks. Special attention should be given to support student teachers in dealing with learners and parents from diverse cultural backgrounds and diverse family backgrounds, such as single parent families, divorced parents; same sex parents; bi-racial parents; parents with disabilities, siblings acting as parents; parents who are terminally ill, parents who are unemployed, foster parents and grandparents acting as parents.

In conclusion, the importance of parent participation needs to be learnt by all student teachers. For their full professional development they need to be exposed to it already during their training, and this is best and most easily accomplished during their teaching practice periods.

\section{References}

Caspe, M., Lopez, M.E., Chu, A. \& Weiss, H.B. (2011). Teaching the teachers: Preparing Educators to engage families for student achievement. Retrieved from http://prod.www. Pta.org/files/lssue_Biref_Teachers_Prep_v2.pdf .

Collins, A., Brown, J.S. \& Holum, A. (1991). Cognitive apprenticeship: Making thinking visible. Ämerican Educator, 15(3): 38-39.

Driessen, G., Smit, F. \& Sleegers, P. (2005). Parental involvement and educational achievement. British Educational Research Journal, $31(4), 509-532$.

Du Plessis, E.C., Marais, P., Van Schalkwyk, A. \& Weeks, F. (2010). Adapt or die: The views of Unisa student teachers on teaching practice at schools. African Education Review, 7(2): 323-341.

Gordon, A.M. \& Browne, K.W. (2011). Beginnings and Beyond. Foundations in Early Childhood Education. (8th ed.). Albany, NY: Delmar.

Lave, J. \& Wenger, E. (1991). Situated learning: Legitimate peripheral participation. Cambridge University Press: Cambridge.

Singh, P., Mbokodi, S.M. \& Msila, V.T. (2004). Black parental involvement in education. South African Journal of Education, 24, 301307.

Van Wyk, N. \& Lemmer, E. (2009). Organising parent involvement in SA schools. Pretoria: Juta.

Wenger, E. 1998. Communities of practice: Learning , meaning, and identity. Cambridge University Press: New York.

Woolfolk, A. (2007). Educational psychology. (10th ed.). New York: Pearson. 